\title{
Effects of nitrogen fertilization in leafy spurge root architecture
}

\author{
KIRSTIN RINGWALL, MARIO E. BIONDINI, AND CAROLYN E. GRYGIEL
}

Authors are undergraduate student, professor, and associate professor, Department of Animal and Range Sciences, North Dakota State University, Fargo, N.D. 58105. Request for reprints should be sent to M.E. Biondini.

Abstract

There is a dearth of information concerning the degree to which the amounts, periodicity, and spatial patterns of $\mathrm{N}$ applications can be manipulated to alter the rooting strategy of leafy spurge, and thus make it more susceptible to chemical and biological controls. This study was designed with the following objectives: (1) determine the effect of patchy $\mathbf{N}$ fertilization on shoot and root biomass, root distribution by depth, root plasticity, and the ratio of coarse vs. fine roots of leafy spurge; and (2) determine how leafy spurge scales root biomass to root lateral spread and root surface area, as well as how these scaling patterns are affected by $\mathbf{N}$ fertilization. The root architecture, plasticity, and response to patchy $\mathbf{N}$ fertilization was evaluated in 3 separate experiments conducted in large containers. Patchy fertilization did not alter the morphological characteristics of leafy spurge roots, but did cause a reduction in root biomass and a drastic change in the distribution of the root surface area within the plant's rooting volume. Fertilization both doubled the percentage of roots located in the top $10 \mathrm{~cm}$ of soil and shifted it toward the fertilized patches.

Key Words: Leafy spurge fertilization, root plasticity, root lateral spread

Leafy spurge (Euphorbia esula L.) has evolved into an extensive weed control issue since first introduced to North America over 130 years ago (Selleck et al. 1962). The majority of current eradication strategies fall into 3 major categories (Lym and Zollinger 1995): physical (mowing, cultivation, competition), biological (grazing, insects), and chemical (herbicides). Leafy spurge eradication, however, has proven difficult primarily due to spurge's ability to persist under adverse conditions, a result of an efficient reproductive system and an extensive root system (Raju et al. 1963, Bowes and Thomas 1978, Galitz and Davis 1983, Messersmith 1983, Lajeunesse et al. 1995, Lym and Zollinger 1995). The heterorhizic complex root system of leafy spurge includes long roots having indeterminate longitudinal growth and the ability to undergo secondary (cambial) growth and short roots having limited cambial activity (Raju et al. 1963). Vertical ("long") roots can grow to depths up to $8.5 \mathrm{~m}$, while horizontal roots can have lateral spreads of up to $5 \mathrm{~m}$ (Lajeunesse et al. 1995, Galitz and Davis 1983). The 2 primary modes of reproduction are through regenerative adventitious root buds and dehis-

Research was funded by the North Dakota EPSCoR Science Bound Awards Program and a grant from the National Science Foundation (DEB-9624928).

Manuscript accepted 30 May 1999.
Resumen

Tenemos al presente un conocimiento limitado de como la cantidad, periodicidad, y distribución espacial de la fertilización con $\mathrm{N}$ puede ser manipulada para alterar la distribución de las raíces de leafy spurge y como consecuencia hacerla mas vulnerable a los controles biologicos y quimicos. Este estudio fue diseñado con los siguientes objetivos: (1) determinar como la aplicación espacialmente irregular de $\mathbf{N}$ afecta la producción de hojas, tallos, $\mathbf{y}$ raíces, la distribución de raíces a diferentes profundidades en el suelo, la plasticidad de las raíces, y la proporción de raíces gruesas en comparación con raices finas de leafy spurge; y (2) determinar la relación entre la biomasa, la expanción lateral y la superficie de las raices en cuestion, y como esa relación es afectada por la fertilización con $\mathbf{N}$. La estructura, plasticidad, y la respuesta de raices a la distribución irregular de $\mathbf{N}$ fue evaluada en 3 experimentos conducidos en macetas grandes. La aplicación espacialmente irregular de $\mathbf{N}$ no afectó las caracteristicas morfologicas de las raices de leafy spurge, pero resultó en una reduccion en la proporción de la biomasa de la planta destinada a las raíces y un drastico cambio en la distribución espacial de las raíces dentro del volumen de suelo explorado por la planta. La fertilización simultaneamente duplicó el porcentaje de raices localizadas en los primeros $10 \mathrm{~cm}$ del suelo, y las concentró en las porciones del suelo fertilizadas.

cence of seed capsules (up to $5 \mathrm{~m}$. from the parent plant) (Galitz and Davis 1983).

Nitrogen $(\mathrm{N})$ plays a key role in the development and competitive abilities of plant species (Haynes et al. 1986), and the root morphological development of spurge has proven highly responsive to variant $\mathrm{N}$, including responses in root:shoot ratios, percentage "long" and lateral roots, and number of root and shoot buds produced (McIntyre and Raju 1967). Recent studies have also shown that soil $\mathrm{N}$ plays a critical role in the overwintering strategy in leafy spurge root systems, and that seasonal fluctuations of root $\mathrm{N}$ are accurate indicators of plant health and determinants of potential regenerative vigour (Lym and Messersmith 1993, McIntyre and Raju 1967, Cyr and Bewley 1989, 1990). Furthermore, fall $\mathrm{N}$ fertilization has been shown to increase the effectiveness of spring applied herbicides (Regimbal and Martin 1985).

A renewed interest has arisen among plant ecologists in determining how root morphology and root plasticity (ability to redirect root growth to areas of high nutrient concentration) can affect plant performance and composition in patchy environments, and how the spatial distribution of nutrients themselves can alter biomass allocation to roots and root architecture (Campbell et al., 1991; Caldwell 1994; Jackson and Caldwell 
1996). Results from these studies have suggested that the ability of plants to compete for soil resources is highly dependent on: (a) the spatial distribution, concentration, and supply rate of soil nutrients; (b) the volume of soil explored by their root system; (c) the density and spatial patterns of root surfaces within the rooting volume; and (d) the rate of nutrient uptake. The available information for most native species and leafy spurge, however, is still quite limited.

Significant amounts of research have been done on leafy spurge physiology, eradication methods, and root organogenesis, but few studies have concerned themselves with elucidating how the competitive ability of leafy spurge can be influenced through interactions among the spatial distribution of soil nutrients (i.e. soil $\mathrm{N}$ ), root architecture, and root plasticity. In particular there is a dearth of information concerning the degree to which the amounts, periodicity, and spatial patterns of $\mathrm{N}$ applications can be manipulated to alter the rooting strategy of leafy spurge, and thus make it more susceptible to chemical and biological controls. This study, thus, was designed with the following objectives:

1. Determine the effect of patchy $\mathrm{N}$ fertilization on shoot and root biomass, root distribution by depth, root plasticity, and the ratio of coarse vs. fine roots.

2. Determine how leafy spurge scales root biomass to root lateral spread and root surface area, as well as how these scaling patterns are affected by $\mathrm{N}$ fertilization.

\section{Materials and Methods}

The root architecture, plasticity, and response to patchy $\mathrm{N}$ fertilization of leafy spurge was evaluated in 3 separate experiments conducted from 1995 to 1997.

\section{Experiments 1 and 2}

Leafy spurge root rhizomes were randomly collected from a sandy soil type in the Sheyenne National Grasslands and planted in $60 \times 60 \times 60 \mathrm{~cm}$ wooden boxes (one $2.5 \mathrm{~cm}$ rhizome, with a bud, per box) equipped with detachable sides and filled with washed river sand from the Buffalo River, N.D. The boxes had two, $2 \mathrm{~cm}^{2}$ hardware mesh panels inserted horizontally at depths of 10 and $30 \mathrm{~cm}$. The mesh was intended to keep the roots in place after the sand had been removed so accurate measurements of vertical and horizontal distributions could be made. Half of the boxes in each experiment were fertilized with Sierra ${ }^{\circledR}$ slow release fertilizer prills (N-P-K:16-8-12 plus minor nutrients) at a rate of $37.5 \mathrm{gN} / \mathrm{m}^{2}$. All prills were located in one side of the box (North), at $7.5 \mathrm{~cm}$ below the surface in a straight line half way between the plant and the outer edge of the container. The purpose of the design was to effectively test the degree to which root architecture was affected by nutrient patchiness. Before adopting this method, a series of preliminary tests were run to determine the design capability for maintaining nutrient patches. Nitrate $\left(\mathrm{NO}_{3}\right)$ was measured (due to its high mobility) for a 4 week trial period using different $\mathrm{N}$ concentrations. Although there was some movement of $\mathrm{NO}_{3}$, we were able to maintain gradients ranging from 15 to 400 ppm.

The experiments were arranged as a completely randomized design with two treatments, fertilized and not-fertilized, and 5 replications per treatment. The experiments were conducted, outdoors, from May to September of 1995 (Experiment 1), and repeated in 1996 (Experiment 2). At the end of each experiment we proceeded as follows: (1) above ground biomass was clipped at the surface level; (2) the sides of the boxes were removed and the sand washed out; and (3) roots were harvested by depth (0-10 and $10-60 \mathrm{~cm})$ and separated in two halves in accordance with the fertilization design. Aboveground biomass and roots were oven-dried for 12 hours at $60^{\circ} \mathrm{C}$ and weighed. In the first experiment, root subsamples by depth and halves were digitized using a Hewlett Packard high resolution scanner and analyzed for total root length, root diameter, and root surface area with the use of a Delta-T Scan imaging system.

\section{Experiment 3}

The third experiment was designed to determine how leafy spurge scales root biomass to root lateral spread. Cylindrical containers $(50 \mathrm{~cm}$ in diameter, $90 \mathrm{~cm}$ in depth) were fitted with 2 cylindrical dividers (15 and $30 \mathrm{~cm}$ in diameter) made of wire netting ( $1 \mathrm{~cm}$ mesh). The mesh system was used to accurately measure root biomass by depth at fixed horizontal distances of $0-7.5,7.5-15$, and $15-25 \mathrm{~cm}$ from the rhizome (one $2.5 \mathrm{~cm}$ rhizome, with a bud, per box). The containers were filled with pure silica sand and planted with leafy spurge rhizomes. Half of the containers were fertilized using the same design outlined in Experiments 1 and 2.

The experiment was organized as a completely randomized design with 2 treatments, fertilized and not-fertilized, and 6 replications per treatment. The experiment was conducted in the greenhouse from May to September (1997). Above ground biomass was clipped at the surface level. Roots were rinsed out while still in the containers and clipped on the basis of 18 locations determined by 3 categories: (1) North side (fertilized) vs. South side (notfertilized); (2) horizontal distance from rhizome $(0-7.5 \mathrm{~cm}, 7.5-15 \mathrm{~cm}$, and $15-25$ $\mathrm{cm})$; and (3) depth $(0-10 \mathrm{~cm}, 10-20 \mathrm{~cm}$, and $20-80 \mathrm{~cm})$. Above and below ground biomass were dried and weighed. Roots were scanned, digitized, and analyzed for total root length, root diameter, and root surface area using the same method discussed in the previous section.

\section{Statistical Analysis}

Statistical differences between fertilized and not-fertilized treatments in terms of above ground biomass, root biomass, and root biomass by depth were analyzed using a t-test. Differences in the proportion of root biomass between the North side (fertilized side in the fertilized treatment) and the South side within each treatment were analyzed using a paired t-test with a null hypothesis of $\mathrm{H}_{\mathrm{o}}=0.5$. The data in this case was transformed using the angular transformation (Bonham 1989). Combined P-values for the 3 experiments, where pertinent, were calculated using the Fisher test (Folks 1984). Differences in the distribution functions of root diameter vs. root surface area among treatments were tested using the Kolmogorov-Smirnov test (Sokal and Rohlf 1969). All results were considered significant at the $\mathrm{P}<0.05$ level.

The scaling relationship of root biomass with root surface area and root lateral spread were analyzed using an allometric model of the form $\boldsymbol{y}=\alpha^{*} \mathbf{R} \mathbf{B}^{\beta}$ where $\boldsymbol{y}$ is either root lateral spread (rls in $\mathrm{cm}$ ) or root surface area $\left(\mathrm{RSA}\right.$ in $\left.\mathrm{m}^{2}\right)$, and $\mathbf{R B}$ is root biomass $(\mathrm{g})$. The equation parameters were estimated with the use of linear regressions on the log-log transformations: $\ln (y)=\ln (\alpha)+\beta * \ln (R B)$.

\section{Results}

Total leafy spurge biomass was unaffected by fertilization in 2 of the 3 experiments (Fig. 1A). In Experiment 2, however, total biomass in the fertilized treatment was more than 3 times higher than in the notfertilized treatment, which resulted in a combined P-value for the 3 experiments of $\mathrm{P}<0.001$. Total root surface area in Experiments 1 and 3 averaged $0.63 \mathrm{~m}^{2}$, but there were no differences between the fertilized and not-fertilized treatment (Fig. 

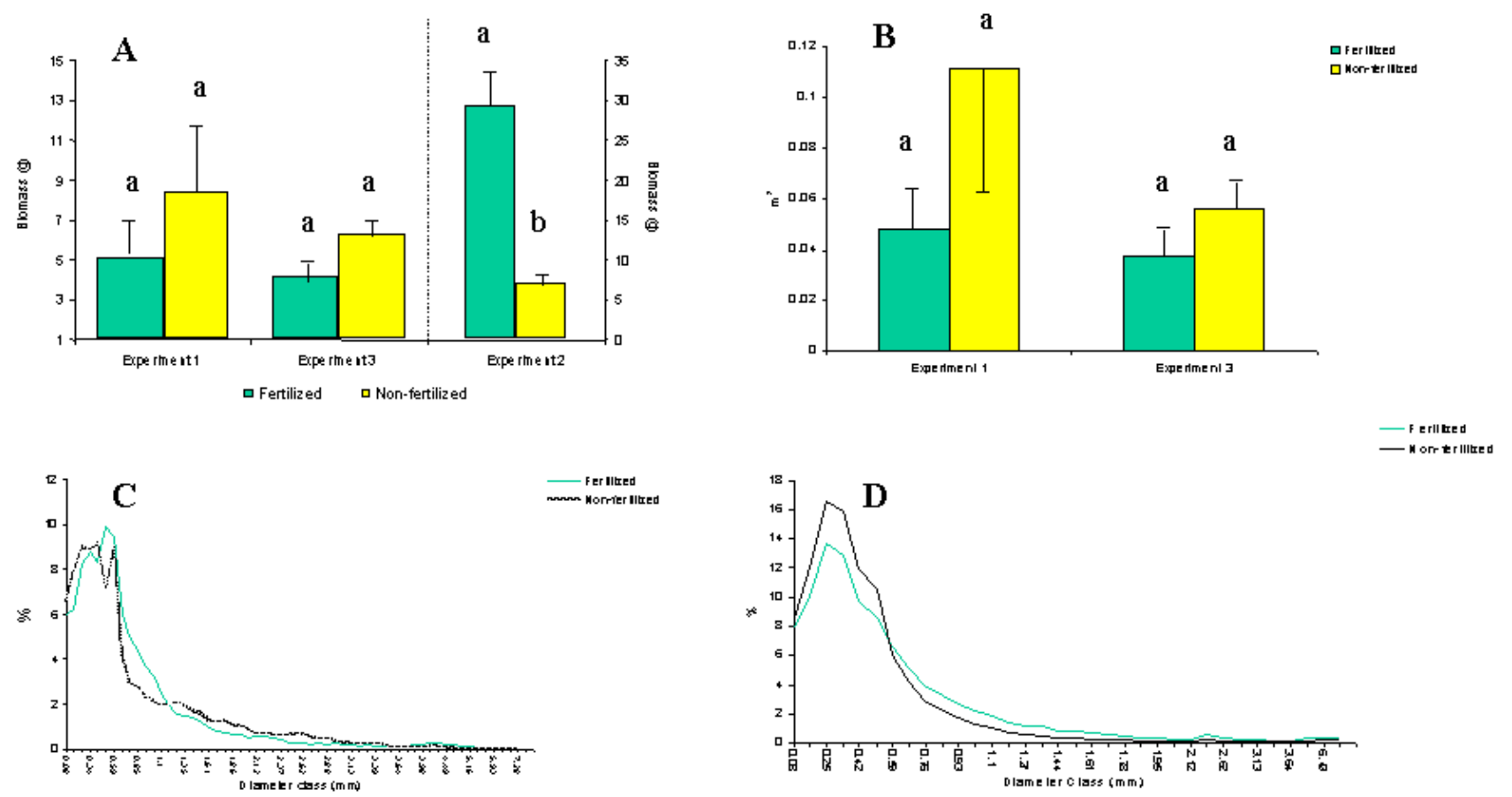

Fig. 1. Effects of fertilization on: A. Total plant biomass (g). B. Total root surface area $\left(\mathrm{m}^{2}\right)$. Percent distribution of total root surface area as a function of root diameter classes (in $\mathrm{mm}$ ) in experiment 1 (C) and experiment 3 (D). Treatments with different letters within an experiment are statistically different at the $P<0.05$ level. Vertical lines represent 1 SE.

1B). Fifty percent of the total root surface area in Experiment 1 and $70 \%$ in Experiment 2 (Figs. 1 C-D) were composed of very fine roots (diameters $<0.5$ $\mathrm{mm})$, but there were no differences in either experiment between the distribution of the root diameter classes of the fertilized vs. the not-fertilized treatments (Figs. $1 \mathrm{C}-\mathrm{D})$.

Root:shoot ratios and the vertical distribution of root biomass were significantly affected by fertilization (Figs. 2 A-C). In 2 of the 3 experiments fertilization reduced root:shoot ratio by an average of 50\%: 1.29 vs. 2.49 (Fig. 2A), and doubled the percentage of root biomass allocated to the first $10 \mathrm{~cm}$ of the soil profile: $31 \%$ vs. $15 \%$ (Figs. 2 B-C). The combined Pvalues for the 3 experiments were $\mathrm{P}<$ 0.001 and $P<0.006$ respectively. An analysis of data from Experiment 3, where 3 depths were available, showed that: (1) $70 \%$ or more of total root biomass was allocated below $20 \mathrm{~cm}$; and (2) leafy spurge allocated only $11 \%$ of root biomass at depths of $10-20 \mathrm{~cm}$, which was unaffected by fertilization (increases in root biomass in the $0-10 \mathrm{~cm}$ came from decreases in the $20-80 \mathrm{~cm}$ depth).

Leafy spurge showed a significant degree of root plasticity (Fig. 2D). In all 3 experiments leafy spurge allocated an average of $75 \%$ of its root biomass to the fertilized side of the containers in the fertilized treatments (Fig. 2D). No differences were found between the North and South sides in the not-fertilized treatments.

There was a significant allometric relationship between root biomass and root surface area, and root biomass and root lateral spread (Table 1). The equations for both the fertilized and not-fertilized treatments were remarkably similar showing very robust and stable scaling patterns. Fertilization, thus, did not affect the total area explored by the root system (Table 1) but simply changed the distribution of the roots within the given area (Figs. 2 B-D).

\section{Discussion and Conlusions}

Total biomass was unaffected by fertilization in 2 out of the 3 experiments, a result that was rather unexpected (Fig. 1A). Also interesting, was the fact that total biomass in Experiments 1 and 3 was very similar even though the experiments differed in the depth of the growth medium $(60 \mathrm{~cm}$ vs. $90 \mathrm{~cm})$, and location: outside vs. greenhouse. The total root surface area of these 2 experiments, furthermore, was also unaffected by fertilization (Fig. 1B). The statistical results in this case were caused by large standard errors, but there seems to be, nevertheless, a definite trend suggesting a decrease in root surface

Table 1. Allometric relationships of root lateral spread $(\mathrm{rsl}$ in $\mathrm{cm})$ and root surface area $(\mathrm{RSA}$ in $\mathrm{m}^{2}$ ) with root biomass ( $R B$ in $\mathrm{g}$ ).

\begin{tabular}{lccll}
\hline \hline Experiment & Treatment & Equation & $\mathbf{R}^{2}$ & P-value \\
\hline Experiment 1 (1995) & Fertilized & $R S A=0.0325 * R B^{0.9243}$ & 0.79 & 0.0028 \\
& Not-Fertilized & $R S A=0.03808^{*} R B^{1.08}$ & 0.85 & 0.025 \\
Experiment 3 (1997) & & & \\
& Fertilized & $R S A=0.0155^{*} R B^{0.95}$ & 0.83 & 0.031 \\
& Not-Fertilized & $R S A=0.0144 * R B^{0.94}$ & 0.94 & 0.032 \\
& Fertilized & $r l s=0.0616^{*} R B^{0.91}$ & 0.80 & 0.0000001 \\
& Not-Fertilized & $r s l=0.0641 * R B^{0.88}$ & 0.85 & 0.0000001 \\
\hline
\end{tabular}



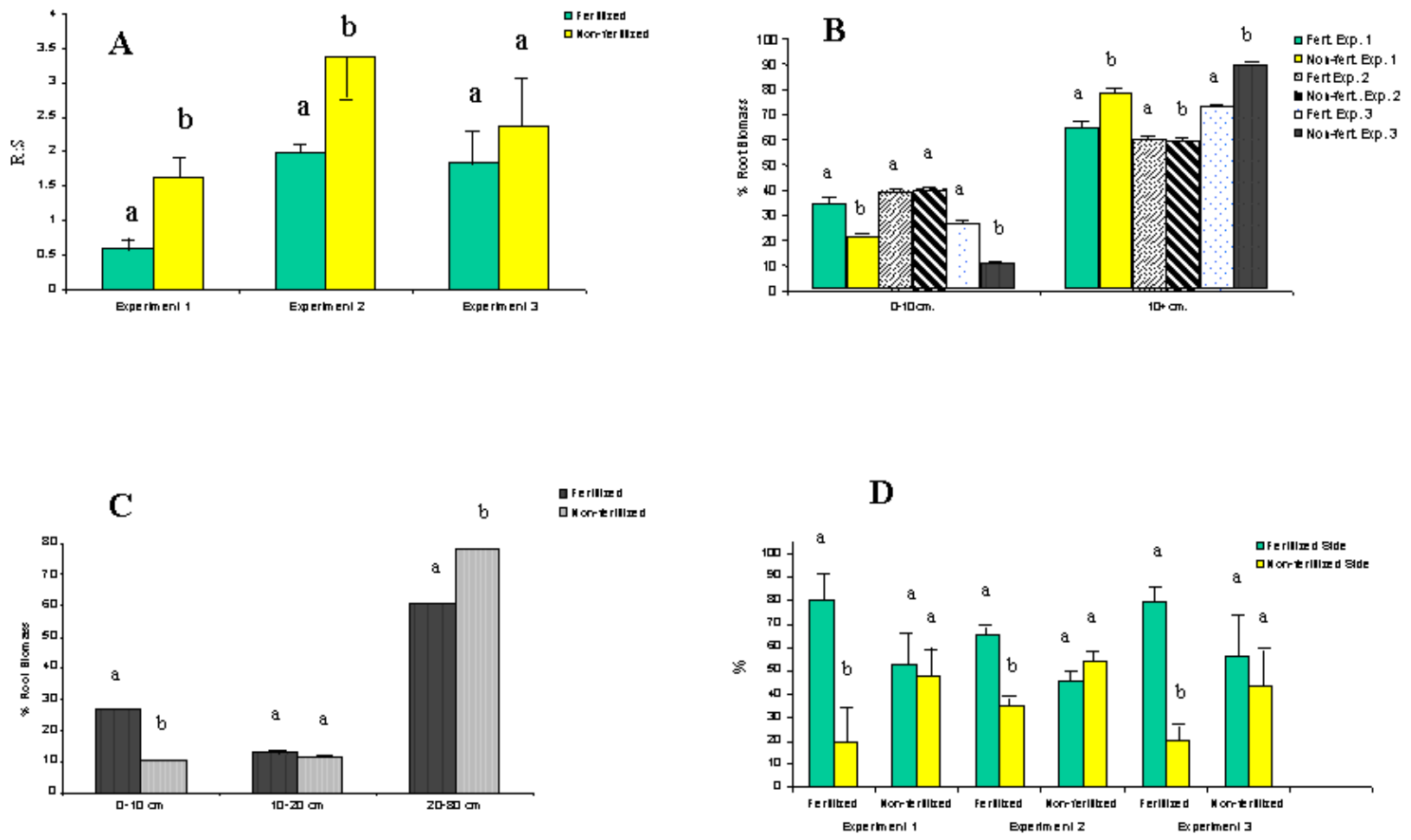

Fig. 2. Effects of fertilization on: A. Root:Shoot $(\mathrm{R}: \mathrm{S})$ ratio. B. Percent root biomass distribution in $0-10 \mathrm{~cm}$ and below $10 \mathrm{~cm}$ of depth for all 3 experiments. C. Percent root biomass distribution in the 0-10, 10-20, and $20-80 \mathrm{~cm}$ of depth for experiment 3. D. Percent biomass allocated to the fertilized and not-fertilized patches in the fertilized treatment and comparable areas in the not-fertilized treatment. Treatments with different letters within an experiment are statistically different at the $P<0.05$ level. Vertical lines represent 1 SE.

area with fertilization (Fig. 1B). This trend, however, was not caused by alterations in root morphology but rather by a decline in root biomass. This interpretation is supported by 3 pieces of evidence: (a) fertilization decreased the amount of plant biomass allocated to roots (Fig. 2A), but did not change the way fertilized and not-fertilized plants scaled root biomass to root surface area (Table 1); (b) there were no changes in average root diameter and diameter distribution classes as a result of fertilization (Figs. 1 C-D); and finally (c) there is a substantial body of both empirical and theoretical data that suggests a trade-off in the way plants allocate biomass to roots: under high nutrient conditions plants increase their biomass allocation to leaves and shoots at the expense of roots, thus reducing their total root surface area (Tilman 1990, Ryser and Lambers 1995, Fransen et al. 1998, but also see Shipley and Peters 1990 for a different perspective). The lack of change in the distribution of root diameter classes as a result of fertilization was rather unexpected (Figs. 1 C-D). For most plants, fertilization tends to increase the average diameter of roots since, when nutrient concentration is not a limiting factor, thicker roots have the small axial conductance and high transport capacity needed to fully exploit a high nutrient environment (Ryser and Lambers 1995).

Patchy fertilization, in summary, did not change the morphological characteristics of leafy spurge roots. Its main effect was a reduction in root biomass and a drastic change in the distribution of the root surface area within the plant's rooting volume (Figs. 2 C-D). Fertilization both doubled the percentage of roots located in the top $10 \mathrm{~cm}$ of soil and shifted it toward the fertilized patches. This level of root plasticity is considerably higher than that observed in many other plants: a 3:1 ratio of root biomass in the fertilized vs. notfertilized patches for leafy spurge (Fig. 2D) vs. an average of 1.5:1 reported in the literature for a variety of grasses and forbs (see Larigauderie and Richards 1994, Caldwell 1994, Fransen et al. 1998 and their respective citations).

The high vertical and horizontal plastic response shown by leafy spurge roots, while advantageous for nutrient acquisition, can potentially constitute a weakness. A considerable advantage of leafy spurge, is that the depth distribution pattern of its root system makes it less susceptible to direct competition from the roots of native species: more than $60 \%$ of the root bio- mass of most grasses and forbs native to the Great Plains is located within the top $30 \mathrm{~cm}$ of the soil profile (Jackson et al. 1996, Sun et al. 1997), whereas the majority of leafy spurge roots are located below $30 \mathrm{~cm}$ (Figs. $2 \mathrm{~B}-\mathrm{C}$ ). We hypothesize that patchy fertilization, by causing a decrease in leafy spurge root biomass, a shift of roots toward the top of the soil profile, and a concentration of these roots in small fertilized patches close to the surface, could increase the effectiveness of chemical and biological control methods because:

(a) Leafy spurge will have to compete for nutrients in a section of the soil profile dominated by the roots of native plants. Intense root competition in patchy environments has been shown to be a major mechanism for plant displacement (Caldwell et al. 1996).

(b) A reduced root system with a higher proportion of roots concentrated in small fertilized patches close to the soil surface, should increase the susceptibility of leafy spurge to drought, and more importantly improve the ability of both herbicides and insects to reach a substantial part of its root system. 


\section{Literature Cited}

Bonham, C. 1989. Measurements for Terrestrial Vegetation. John Wiley \& Sons. New York.

Bowes, G.G. and A.G. Thomas. 1978 . Longevity of leafy spurge seeds in the soil following various control programs. J. Range Manage. 31: 137-140.

Caldwell, M.M. 1994. Exploiting nutrients in fertile soil microsites. p. 325-347. In: Caldwell M.M. (ed.). Exploration of Environmental Heterogeneity by Plants. Acad. Press Inc., New York.

Caldwell, M.M., J.H. Manwaring, and S.L. Durham. 1996. Species interactions at the level of fine roots in the field: influence of soil nutrient heterogeneity and plant size. Oecologia 106:440-447.

Campbell, B.D, J.P. Grime, and J.M.L. Mackey. 1991. A trade-off between scale and precision in resource foraging. Oecologia 87:532-538.

Cyr, D.R. and J.D. Bewley. 1989. Carbon and nitrogen reserves of leafy spurge (Euphorbia esula) roots as related to overwintering strategy. Physiol. Plant 77: 67-72.

Cyr, D.R. and J.D. Bewley. 1990. Seasonal variation in nitrogen storage reserves in the roots of leafy spurge (Euphorbia esula) and responses to decapitation and defoliation. Physiol. Plant 78: 361-366.

Folks, J.L. 1984. Combination of independent tests. p. 113-122. In: P.R. Krishnaiah and P.K. Sen (ed.). Handbook of Statistics 4. Nonparametric Methods. North Holland, N.Y.

Fransen, B, H. de Kroon, and F. Berendse. 1998. Root morphological plasticity and nutrient acquisition of perennial grass species from habitats of different nutrient availability. Oecologia 115:351-358.
Galitz, D.S. and D.G. Davis. 1983. Leafy spurge physiology and anatomy. North Dakota Farm Res. Bull. 40: 20-26. North Dakota State Univ., Fargo, N.D.

Haynes, R.J., K.C. Cameron, K.M. Goh, and R.R. Sherlock. 1986. Mineral Nitrogen in the Plant-Soil System. Academic Press Inc., London.

Jackson, R.B. and M.M Caldwell. 1996. Integrating resource heterogeneity and plant plasticity: modelling nitrate and phosphate uptake in a patchy soil environment. J. Ecol. 84: 891-903.

Jackson, R.B., J. Canadell, J. R. Ehleringer, H. A. Mooney, O. E. Sala, and E. D. Schulze. 1996. A global analysis of root distributions for terrestrial biomes. Oecologia 108:389-411.

Lajeunesse, S., R., Sheley., R. Lym, D. Cooksey, C. Duncan, J. Lacey, N. Rees, and M. Ferrell. 1995. Leafy spurge biology, ecology, and management. Montana State Univ. Ext. Serv. Circular W-1088 (EB 134). Bozeman, Mont.

Larigauderie, A. and J. H. Richards. 1994. Root proliferation characteristics of seven perennial arid-land grasses in nutrientenriched microsites. Oecologia 99:102-11.

Lym, R.G. and C.G. Messersmith. 1993. Fall cultivation and fertilization to reduce winter hardiness of leafy spurge. Weed Sci. 41: 441446.

Lym, R.G. and R.K. Zollinger. 1995. Integrated management of leafy spurge. North Dakota State Univ. Ext. Service Bull. W-866. North Dakota State Univ., Fargo, N.D.

McIntyre, G.I. and M.V.S. Raju. 1967. Developmental studies on Euphorbia esula: some effects of the nitrogen supply on the growth and development of the seedling. Can. J. Bot. 45: 975-984.
Messersmith, C.G. 1983. The leafy spurge plant. North Dakota Farm Res. Bull. 40: 3-7. North Dakota State Univ., Fargo, N.D.

Raju, M.V.S., T.A. Steeves, and R.T. Coupland. 1963. Developmental studies on Euphorbia esula: morphology of the root system. Can. J. Bot. 41: 579-589.

Regimbal, G.A. and Martin, A.R. 1985. The influence of growth regulators and nitrogen on leafy spruge (Euphorbia esula) control with picloram. Weed Sci. 33: 109-113.

Ryser, P. and H. Lambers. 1995. Root and leaf attributes accounting for the performance of fast- and slow-growing grasses at different nutrient supply. Plant and Soil 170:251-265.

Selleck, G.W., R.T. Coupland, and C. Frankton. 1962. Leafy spruge in Saskatchewan. Ecol. Monog. 32:1-29.

Shipley B. and R.H. Peters. 1990. A test of Tilman model of plant strategies: relative growth rate and biomass partition. The Amer. Nat. 136:139-153.

Sokal, R.R. and F.J. Rohlf. 1969. Biometry. W.H. Freeman \& Company. San Francisco, Calif.

Sun, G, D. P. Coffin, and W. K. Lauenroth. 1997. Comparison of root distributions of species in North American grasslands using GIS. J. Veg. Sci. 8:587-596.

Tilman, D. 1990. Constraints and tradeoffs: toward a predictive theory of competition and succession. Oikos 58:3-15. 